From time to time, articles are published in AJE that evoke comments from readers. In Response is reserved for this dialogue. Contributions should be to the point, concise, and easy for readers to track to targeted articles. Comments may be positive or negative, but if the latter, then keep them at least relatively nice! Personal attacks and offensive, degrading criticisms will not be published. Please keep the length of comments to the minimum essential

\title{
The Issue of Advocacy in Evaluations
}

\section{ERNEST R. HOUSE and KENNETH R. HOWE}

Chelimsky (1998) has provided us with a valuable synthesis of what she has learned over the past decades as director of one of the most visible and highly regarded evaluation offices in Washington, the Program Evaluation and Methodology Division (PEMD) of the General Accounting Office (GAO). Of course, she is speaking from experience in one particular set of circumstances. In fact, one of her conclusions is that specific political conditions have strong effects on how evaluations are done, which suggests we should generalize to other situations with caution. Experiences elsewhere might be different.

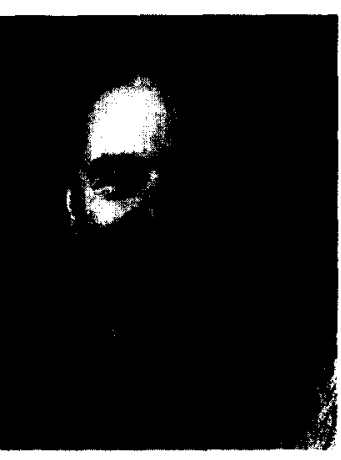

Ernest R. House

In her article, she contrasts experience with theory, emphasizing that experience is not always consonant with evaluation theory and that theory is of dubious value. But perhaps the problem here is with what she thinks theory can provide. We develop this point in terms of what she says about advocacy, a major theme in her paper. Let's begin with experience rather than theory.

\footnotetext{
The need in a political environment is not for still another voice to be raised in advocacy, but rather for information to be offered for public use that's sound, honest, and without bias toward any cause. Policy makers in the Congress expect evaluators to play precisely such a role and provide precisely this kind of information.... Yet we've seen recently attempts to rationalize advocacy by evaluators, and this idea has some roots in theory....Our experience in PEMD was that advocacy of any kind destroys the evaluators' credibility and has no place in evaluation (Chelimsky, 1998, pp. 39, 40).
}

Ernest R. House - School of Education, Laboratory of Policy Studies, University of Colorado, Campus Box 249, Boulder, CO 80309.

American Journal of Evaluation, Vol. 19, No. 2, 1998, pp. 233-236. 
At the same time, she says, Congress rarely asks serious policy questions about Defense Department programs. And this has been especially true with questions about chemical warfare. In 1981 when she initiated studies on chemical warfare programs she found that there were two literatures. One was classified, favorable to chemical weapons, and presented by the Pentagon in a one-sided way to Congress. The other was critical, dovish, public, and not even considered by Congressional policy makers.

On discovering this situation, PEMD conducted a synthesis of all the literature, which, she says, "had an electrifying effect on Members of Congress who were confronting certain facts for the first time." (p. 43). This initial document led to more evaluations, publicity, and eventually contributed to the international chemical weapons agreements.

This chemical warfare work was predicated on analyzing the patterns of partisanship of the previous research, understanding the political underpinnings of the program and the evaluation, and trying "to integrate conflicting values" into the evaluation-which she recommends for all such studies. This is a very intelligent approach, it seems to us. Our question is, what framework guided her to conduct the study in this fashion? No stakeholder group was inciting her to do so. The Pentagon pushed its own information, and the anti-chemical doves theirs. Chelimsky had to have some framework, intuitive though it might be, for guiding her as to what to do.

We think the framework must be something like this: Include conflicting values and stakeholder groups in the study. Make sure all major views are sufficiently included and represented. Bring conflicting views together so there can be deliberation and dialogue about them among the relevant parties. Not only make sure there is sufficient room for dialogue to resolve conflicting claims, but help the policy makers and media resolve these claims by sorting through the good and bad information. Bring the interests of beneficiaries to the table if they are neglected. Assuming that our characterization of their framework is reasonably accurate, we are told how the PEMD evaluators accomplished all this.

Now all of this analysis and interpretation requires many judgments and decisions on the part of the evaluators as to who is relevant, what is important, what is good information, what is bad, how to handle the deliberations among policy makers, how to handle the media, what the political implications are, and so on. The evaluators unavoidably become heavily implicated in the findings, even if they themselves do not formulate the actual conclusions of the study. Their intellectual fingerprints are all over the place.

Furthermore, the entire evaluation is guided by a particular conception of the role of evaluation in public policy. Is this advocacy on the part of the evaluators? We would say no, even though their work is heavily value-laden and incorporates judgment. It is not advocacy, such as taking the Pentagon or the dove's side of the issue at the beginning of the study, and championing only one side or the other. After all, if the Congress is so heavily slanted towards the Pentagon, it would make canny political sense to keep on their good side since they are the clients. Presumably, this is what client-oriented evaluators (e.g., Patton, 1996) would have done. Or, they might have constructed value summaries endorsed by Shadish et al. (1995), "If you are in favor of chemical weapons, $\mathrm{X}$ is the action to take, but if you are opposed, $\mathrm{Y}$ is the action to take," and turned these over to policy makers.

But the evaluators did something more risky and more defensible-they included all sides, not just the Pentagon side, in the study. This was the proper thing to do, in our view. Now it seems to us that the conduct of this study is consistent with theory, not opposed to it. Or at least the theory we want to endorse. We suggest three criteria for evaluations to be properly balanced in terms of values, stakeholders, and politics, in what we call the deliberative 
democratic approach (House and Howe, forthcoming). First, the study should be inclusive so as to represent all relevant views, interests, values, and stakeholders. No important ones should be omitted. In the chemical warfare case, the views critical of chemical warfare programs were omitted originally and only the favorable Pentagon views were included, thus biasing conclusions in the previous studies.

Second, there should be sufficient dialogue with the relevant groups so that the views are properly and authentically represented. Getting authentic views is not always easy to do for various reasons, but it is often critical. "Paying attention to what the beneficiaries of a program think about it is a hallmark of a credible study, and has nothing to do with advocating for those beneficiaries" (Chelimsky, 1998, p. 47). In this case the potential victims of chemical warfare can hardly be present. Someone must represent their interests. Presumably, including stakeholders and talking to them when possible is not advocacy in Chelimsky's view.

Third, there should be sufficient deliberation to arrive at proper findings. In this case the deliberation was long and productive, involving evaluators, policy makers, and eventually the media. We are not told details. Deliberation might involve ways to protect evaluators or others from powerful stakeholder pressures, which can seriously inhibit discussion, as Chelimsky notes. Proper deliberation cannot be simply a free-for-all among stakeholders. If it is, the powerful win; deliberation is aborted.

Designing and managing all this involves considerable judgment on the part of the evaluators. And we see no way around it. One can be guided by intuition, as Chelimsky and her colleagues seemed to be, or try something more explicit, as we are suggesting in our deliberative democratic approach. Actually, Chelimsky does advance a conception of the public interest, i.e., that the evaluation should be judged by "its success as a provider of objective information in the public interest."

And she goes further: "My guess is that the much greater risk to our field is not lack of use for the right reasons, but rather a declining capability or willingness to question the conventional wisdom, which is our most important task and the best justification for our work." (p. 57). Here she is correct in pointing to much current theory which does indeed support the status quo, however implicitly. Such theories incorporate what we call the "received vicw" of values, an incorrect view, as it turns out (House and Howe, forthcoming).

So isn't she an advocate for her particular conception of the public interest and of evaluation's role in it? If not, how does this view differ from advocacy? Advocacy in one sense means taking the views or interests of one group and always championing them over others, regardless of the findings of the evaluation. For example. Chelimsky and her colleagues could have taken either the views of the Pentagon or those of the doves without balancing out the two. This would be one kind of advocacy. She hasn't done this.

On the other hand, if advocacy means using or endorsing any particular frameworks or values, she might be accused of advocacy for her particular conception of the public interest, one not everyone would agree with. In fact, she says all evaluators should conduct evaluations with informing the public interest in mind. She might be an advocate in that sense of endorsing an overall framework. We believe that all evaluators must embrace some conception of the public interest, of democracy, and of social justice, even if these conceptions are implicit. They cannot avoid it in the conduct of their studies.

In this sense evaluators should be advocates-for democracy and the public interest-and for what this presupposes - an egalitarian conception of justice. In our view, the public interest is not static and often is not initially identifiable, but emerges (or ought to) through properly constrained democratic processes in which evaluation plays a role. Interestingly, because 
evaluators should be advocates for democracy and the public interest, they should not be advocates for particular stakeholder groups in which perceived interests are viewed as impervious to evidence and are promoted come what may. (Greene, 1997, uses the sense of advocacy one way and Chelimsky, 1998, the other, unfortunately talking at cross purposes.) Nor should evaluators play the role of neutral facilitators among advocates of competing "value summaries," or stakeholder "constructions," in our view.

How does this chemical warfare case differ from evaluation of social programs? Not much, except in the particular views and stakeholders involved. In Madison and Martinez's (1994) evaluation of health care services on the Texas Gulf Coast, they identified the major stakeholders as the recipients of the services (elderly African-Americans), and the providers of the services (mostly white physicians and nurses), plus representatives from African-American advocacy groups. Each group had different views, with the elderly saying the services were not sufficiently accessible, and the medical providers saying the elderly lacked knowledge about the services.

Is it advocacy for particular groups, let us say the African-Americans, to include them in the study? We think it is not advocacy, but rather balancing out the values and interests of the study. All perspectives should be represented-the democratic view-and evaluators should try to determine who is correct. Nor is it advocacy to enter the study with the understanding that African American views are often excluded in such studies. That is documented history, and the evaluator should be alert to such contingencies.

In such an evaluation, there is no grand determination of the rights of elderly AfricanAmericans versus those of white professionals in society at large. That is beyond the scope of most evaluations. Evaluators must determine what is happening with these services in this place at this time, a more modest task. Advocacy in the misdirected sense would mean that one enters the study already convinced that the African-Americans are right and the service providers wrong, or vice versa, regardless of the facts. This is not the proper role for evaluators.

Our notion of the public interest in evaluation is one of deliberative democracy in which the evaluation informs public opinion objectively by including views and interests, promoting dialogue, and fostering deliberation directed towards reaching valid conclusions. Objectivity is supplied by inclusion, dialogue, and deliberation and by the evaluation expertise the professional evaluator brings to bear. Evaluators cannot escape being committed to some notion of democracy and the public interest. The question is how explicit and defensible it is.

\section{REFERENCES}

Chelimsky, E. (1998). The role of experience in formulating theories of evaluation practice. American Journal of Evaluation, 19(1), 35-55.

Greene, J. C. (1997). Evaluation as advocacy. Evaluation Practice, 18(1), 25-35.

House, E. R. \& Howe, K. R. (forthcoming). Values in evaluation and social research. Thousand Oaks, CA: Sage Publications.

Madison, A. \& Martinez, V. (1994). Client participation in health planning and evaluation: An empowerment education strategy. Paper presented at the American Evaluation Association, Boston, November 3.

Patton, M. Q. (1996). Utilization-focused evaluation, new century edition. Thousand Oaks, CA: Sage.

Shadish, W., Cook, T. \& Leviton, L. (1995). Foundations of program evaluation. Newbury Park, CA: Sage. 